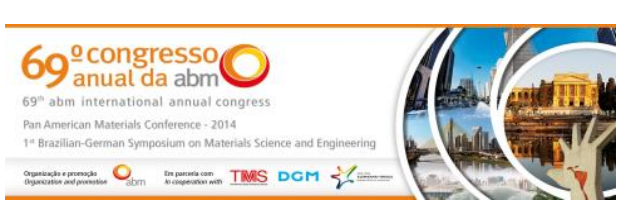

Tema: Lavra e tratamento de minérios

\title{
COMPARAÇÃO DE DIFERENTES AMINAS NA FLOTAÇÃO CATIÔNICA REVERSA DE MINÉRIO DE FERRO DA REGIÃO NORTE DE MINAS GERAIS*
}

\author{
Henrique de Siqueira Queiroz ${ }^{1}$ \\ Érica Linhares Reis ${ }^{2}$ \\ Júnia Mayane Sales ${ }^{3}$ \\ Gustavo Ferreira Correia ${ }^{4}$
}

\begin{abstract}
Resumo
A indústria mineral brasileira é uma das maiores produtoras de minério de ferro do mundo e as reservas do país estão cada vez com teores mais baixos. Por isso hoje são necessários estudos para viabilizar a explotação de jazidas de baixos teores. Utilizando-se de minérios mais pobres, faz-se necessário uma maior cominuição para beneficiamento do minério. Com uma menor granulometria do material, o processo de flotação passa a ter importante papel no beneficiamento por ser mais tolerável aos finos. O objetivo deste trabalho foi testar diferentes coletores catiônicos, especificamente aminas, utilizados na etapa de flotação reversa de um minério de ferro da região do Vale do Rio Pardo. As amostras utilizadas nos testes são provenientes da remoagem que, pelo circuito de beneficiamento, alimenta a flotação de finos. Foram testados como coletores as aminas EDA, EDA3 e EDA 3C da Clariant. A amina que obteve melhor desempenho foi a Flotigam EDA $3 C$ que obteve concentrado final com $67,4 \% \mathrm{Fe}$ e $1,76 \%$ de $\mathrm{SiO}_{2}$, e recuperação metalúrgica de ferro de 92,14\%.
\end{abstract}

Palavras-chave: Flotação; Minério de ferro; Aminas.

\section{DIFFERENT AMINES IN REVERSE FLOTATION IRON ORE FROM REGION NORTH OF MINAS GERAIS}

\begin{abstract}
The mineral industry is a major producer of iron ore reserves in the world and the country are increasingly with iron lower grade. Studies to enable the exploitation of deposits of low grade is necessary. Using ores iron low grade, it is necessary for greater comminution ore processing. With a smaller particle size of the material, the flotation process has an important role in the processing to be more tolerable to fine. The objective of this study was to test different cationic collectors, specifically amines , used in reverse flotation step in a iron ore from Vale do Rio Pardo, Minas Gerais, Brazil. The samples used in this study are from regrind that the beneficiation circuit feeds the flotation of fine. The following amines were tested: EDA, EDA $3 \mathrm{C}$ and EDA3 (Clariant). The amine which performed better was the Flotigam EDA 3C who got the final concentrate with $67.4 \% \mathrm{Fe}$ and $1.76 \% \mathrm{SiO}_{2}$, and recovery is $92.14 \%$.

Keywords: Iron ore; Amines; Flotation.

1 Engenheiro, Escola de Minas, UFOP, Ouro Preto, MG, Brasil.

2 Professora, Departamento de Engenharia de Minas, Escola de Minas, UFOP, Ouro Preto, MG,

Brasil.

3 Engenheira de Processos, Sul America de Metais S/A- SAM, Salinas, MG, Brasil.

4 Graduando em Engenharia de Minas, Escola de Minas, UFOP, Ouro Preto, MG, Brasil.
\end{abstract}

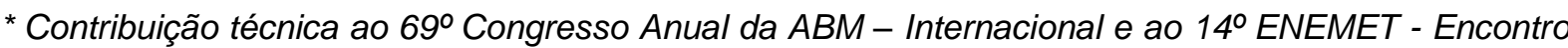
Nacional de Estudantes de Engenharia Metalúrgica, de Materiais e de Minas, 21 a 25 de julho de 2014, São Paulo, SP, Brasil.
} 


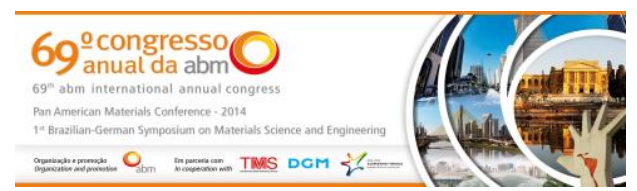

\section{INTRODUÇÃO}

O mercado de minério de ferro é de grande importância por se tratar de um dos elementos químicos de maior utilização na vida do homem desde a antiguidade. No Brasil, em especial, trata-se de um dos maiores setores industriais nacionais que possuem indústrias com grandes instalações e que utilizam intensivamente recursos naturais, insumos químicos e energia.

Com depósitos de minérios de altos teores cada vez menores, torna-se necessária a viabilização da explotação de minérios de baixos teores. Para isto, faz-se necessária uma maior cominuição do material para obter a liberação adequada do mineralminério em relação aos minerais de ganga. Com uma menor granulometria das partículas minerais, o processo de concentração por flotação aumenta sua importância por ser o processo que tem mostrado maior eficiência de concentração de partículas finas.

O processo de flotação possui grande precisão na separação, pois utiliza reagentes bastante seletivos que modificam a molhabilidade de certos minerais, facilitando assim a separação das espécies. Os reagentes mais utilizados na flotação catiônica reversa de minérios de ferro são: amidos, aminas e hidróxido de sódio. A amina é o coletor catiônico comumente utilizado na flotação reversa de minério de ferro.

Segundo Baltar [1] as aminas são derivadas da amônia pela substituição de um ou mais átomos de hidrogênios por cadeias hidrocarbônicas. Quando ocorre a substituição de apenas um átomo de hidrogênio a amina é classificada como primária, e assim, sucessivamente.

De acordo com Wills [2] as aminas são adsorvidas nas superfícies minerais, principalmente devido à atração eletrostática entre a extremidade polar do coletor e a carregada dupla camada elétrica na superfície mineral. Tais forças não são tão fortes ou irreversíveis como as forças químicas, características dos coletores aniônicos, que tendem a ser relativamente fracos em termos de poder de coletor.

Papini [3] estudou o efeito do tipo de amina na flotação catiônica reversa de um minério itabirítico, concluiu que as eteraminas são os melhores coletores para esse tipo de minério sendo que aquelas com menores graus de neutralização apresentaram maiores índices de seletividade. Os valores de neutralização de aminas mais largamente empregados situam-se na faixa de 30 a $70 \%$.

Cassola e Bartalini [4] realizaram estudo sobre o comportamento de diferentes minérios de ferro frente a inovações nos coletores utilizados na etapa de flotação reversa. O desempenho das aminas avaliadas para quatro diferentes minas possibilitaram maior recuperação metalúrgica para três delas, mantendo a qualidade do concentrado com relação ao teor de sílica. As aminas utilizadas foram: Flotigam EDA, EDA 3 e EDA C da Clariant.

O presente trabalho teve como objetivo testar por flotação em bancada, três aminas e verificar qual resulta em maior coleta de sílica para finos de um minério de ferro da região do Vale do Rio Pardo situada no norte de Minas Gerais.

\section{MATERIAIS E MÉTODOS}

\subsection{Amostra de Minério de Ferro}

A amostra em estudo é um "blend" que segundo os critérios geológicos e de lavra do projeto representa o minério a ser explotado nos primeiros seis anos de operação da mina. A composição química e distribuição granulométrica da fração menor que

\footnotetext{
* Contribuição técnica ao $69^{\circ}$ Congresso Anual da ABM - Internacional e ao 14ํㅡㄹ ENEMET - Encontro Nacional de Estudantes de Engenharia Metalúrgica, de Materiais e de Minas, 21 a 25 de julho de 2014, São Paulo, SP, Brasil.
} 


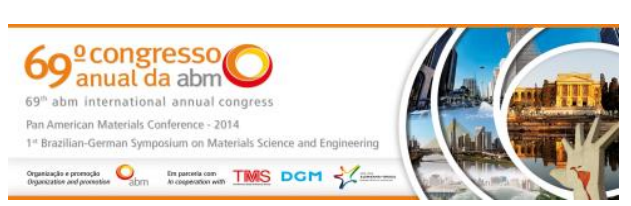

$74 \mu \mathrm{m}$ são apresentadas na Tabela 1 e Figura 1. O estudo foi realizado com uma amostra de minério de ferro da alimentação do circuito de flotação de finos, que se localiza após a remoagem do material pré-concentrado.

Tabela 1. Composição química da amostra de finos do minério de ferro da região do Vale do Rio Pardo.

\begin{tabular}{c|c|c|c|c|c|c|c|c|c|c}
\hline \multicolumn{10}{c}{ Análise Química Global (\%) } \\
\hline $\mathrm{Fe}$ & $\mathrm{SiO}_{2}$ & $\mathrm{Al}_{2} \mathrm{O}_{3}$ & $\mathrm{CaO}$ & $\mathrm{TiO}_{2}$ & $\mathrm{MgO}$ & $\mathrm{K}_{2} \mathrm{O}$ & $\mathrm{Na}_{2} \mathrm{O}$ & $\mathrm{P}$ & $\mathrm{Mn}$ & $\mathrm{PPC}$ \\
\hline 64,20 & 5,78 & 0,92 & 0,42 & 0,13 & 0,23 & 0,07 & $<0,1$ & 0,04 & 0,75 & 0,59 \\
\hline
\end{tabular}

O teor de ferro da amostra é de $64,20 \%$ e de sílica 5,78\%. O material possui cerca de $80 \%$ das partículas abaixo de $45 \mu \mathrm{m}$ (325 mesh).

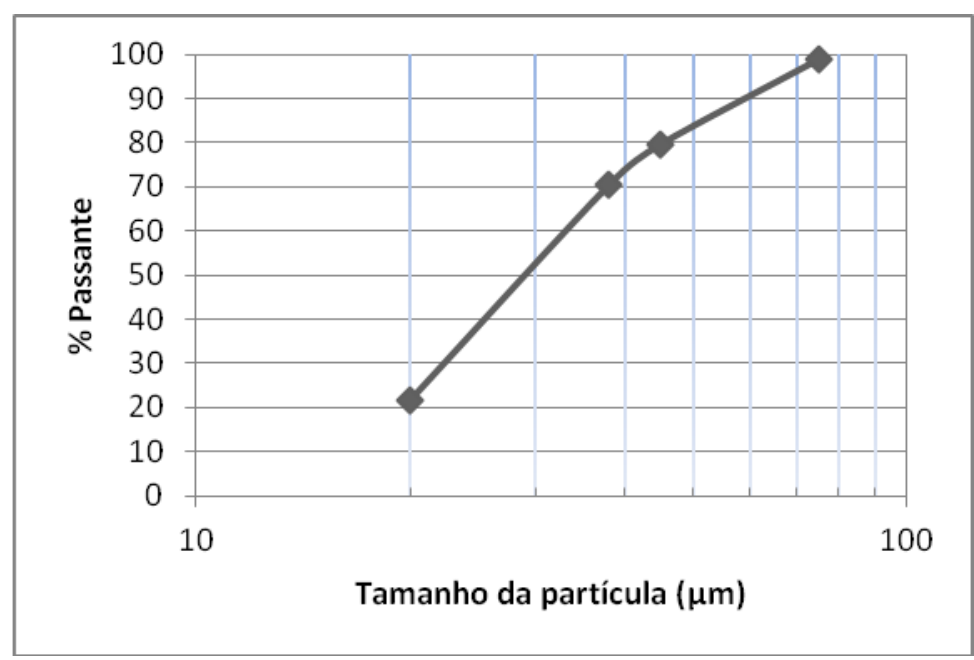

Figura 1. Distribuição granulométrica da amostra de finos do minério de ferro da região do Vale do Rio Pardo.

\subsection{Ensaios de flotação em bancada}

Os testes foram realizados em célula de flotação da marca CDC. Para cada ensaio foi utilizado $1 \mathrm{~kg}$ de amostra em uma cuba de $2 \mathrm{~L}$. Os ensaios foram realizados com $45 \%$ de sólidos na polpa. O trabalho foi realizado com amido de milho (Flokit da fabricante Kowalski Alimentos S/A) cáustico e cozido ( $5 \%$ p/p) com dosagem de $1000 \mathrm{~g} / \mathrm{t}$, e condicionamento de 5 minutos. $\mathrm{O}$ pH em 10,5 sempre corrigida com solução de $\mathrm{NaOH}$ da Sulfal Química Ltda (1\% p/v). As aminas utilizadas são classificadas como etermonoaminas. Todas as aminas foram fornecidas pela Clariant, o Quadro 1 apresenta alguns dados sobre as aminas utilizadas. A solução de amina foi preparada na concentração de $5 \%$ (p/p) com dosagem de $10 \mathrm{~g} / \mathrm{t}$ e condicionada por um minuto. Depois de transcorrido o tempo de 1 minuto, a vazão de ar foi regulada para $4,5 \mathrm{NI} / \mathrm{min}$. A camada de espuma formada foi coletada com as paletas até a visualização da exaustão da espuma.

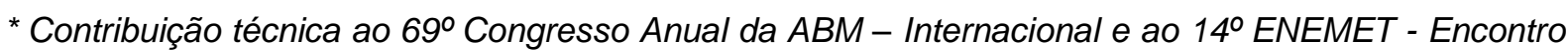
Nacional de Estudantes de Engenharia Metalúrgica, de Materiais e de Minas, 21 a 25 de julho de 2014, São Paulo, SP, Brasil.
} 


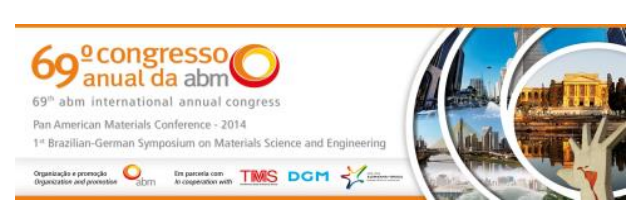

Quadro 1. Coletores testados na flotação (adaptado de Cassola e Bartalini) [4]

\begin{tabular}{|c|c|c|c|c|}
\hline $\begin{array}{c}\text { Coletor } \\
\text { (etermonoamina) }\end{array}$ & $\begin{array}{c}\text { Característica } \\
\text { da cadeia }\end{array}$ & $\begin{array}{c}\text { Quantidade } \\
\text { de carbono na } \\
\text { cadeia }\end{array}$ & $\begin{array}{c}\text { Grau de } \\
\text { neutralização } \\
(\%)\end{array}$ & Comentários \\
\hline Flotigam EDA & $\begin{array}{l}\text { Média- } \\
\text { ramificada }\end{array}$ & $10 \mathrm{C}$ & 50 & \multirow{3}{*}{$\begin{array}{l}\text { Coletores para } \\
\text { flotação de } \\
\text { quartzo e } \\
\text { minérios } \\
\text { silicatados com } \\
\text { características } \\
\text { ácidas }\end{array}$} \\
\hline Flotigam EDA-3 & $\begin{array}{c}\text { Média- } \\
\text { ramificada }\end{array}$ & $10 \mathrm{C}$ & 30 & \\
\hline $\begin{array}{l}\text { Flotigam EDA- } \\
3 \mathrm{C}\end{array}$ & $\begin{array}{l}\text { Média- } \\
\text { ramificada }\end{array}$ & $9 \mathrm{C}$ & 30 & \\
\hline
\end{tabular}

As análises químicas dos produtos flotado e afundado foram realizadas por fluorescência de raios-X no laboratório químico da SGS Geosol Laboratórios Ltda. Os resultados obtidos foram utilizados para os cálculos de balanço de massa e metalúrgico.

\section{RESULTADOS E DISCUSSÃO}

$\mathrm{Na}$ Figura 2 estão apresentados os resultados de recuperação mássica e recuperação metalúrgica de ferro nos concentrados dos ensaios com as diferentes aminas. A amina que obteve os melhores resultados em recuperação mássica e metalúrgica de ferro foi a Flotigam EDA 3, com valores de 92,19\% e 93,33\%, respectivamente. Vale ressaltar que o coletor Flotigam EDA 3C também conseguiu atingir o objetivo inicial que era de recuperação metálica de ferro acima de $90 \%$, para este coletor o valor obtido foi igual a $92,14 \%$.

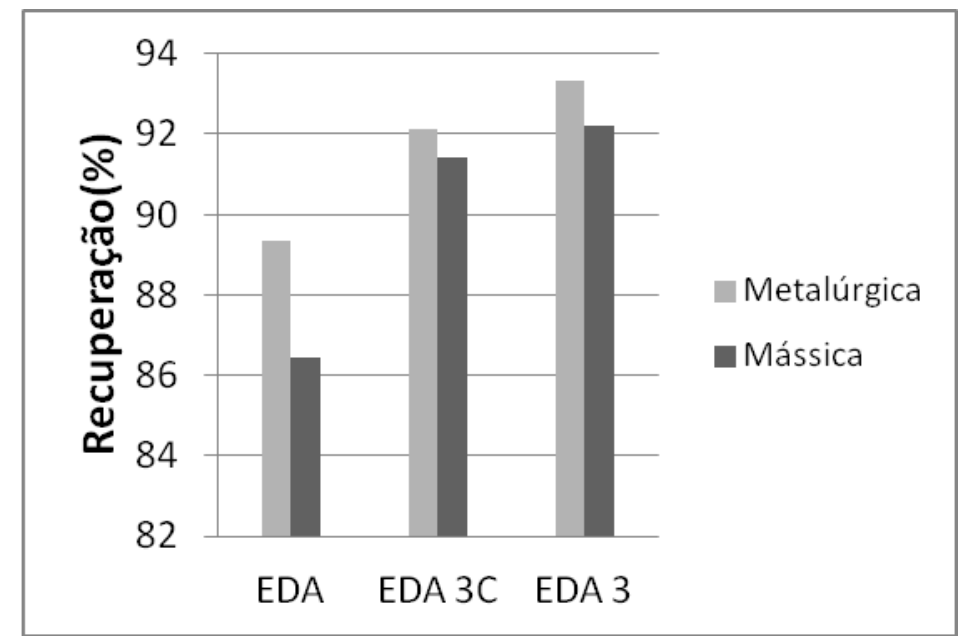

Figura 2. Recuperação mássica e recuperação metalúrgica de ferro no concentrado dos ensaios com diferentes aminas.

$\mathrm{Na}$ Figura 3, são apresentados os resultados de recuperação metálica de $\mathrm{Fe}$ e $\mathrm{SiO}_{2}$ para as diferentes aminas. Utilizando a amina EDA 3C foi obtido os menores valores de recuperação de sílica no concentrado, cerca de 54\%. Para esta mesma amina foi obtido resultado intermediário de recuperação de ferro $(92,14 \%)$ quando comparada as aminas, EDA e EDA3. O maior valor de recuperação de sílica no concentrado foi observado no ensaio utilizando a amina EDA3, com valores em torno de $74 \%$.

\footnotetext{
* Contribuição técnica ao $69^{\circ}$ Congresso Anual da ABM - Internacional e ao 14ํㅡㄹ ENEMET - Encontro Nacional de Estudantes de Engenharia Metalúrgica, de Materiais e de Minas, 21 a 25 de julho de 2014, São Paulo, SP, Brasil.
} 

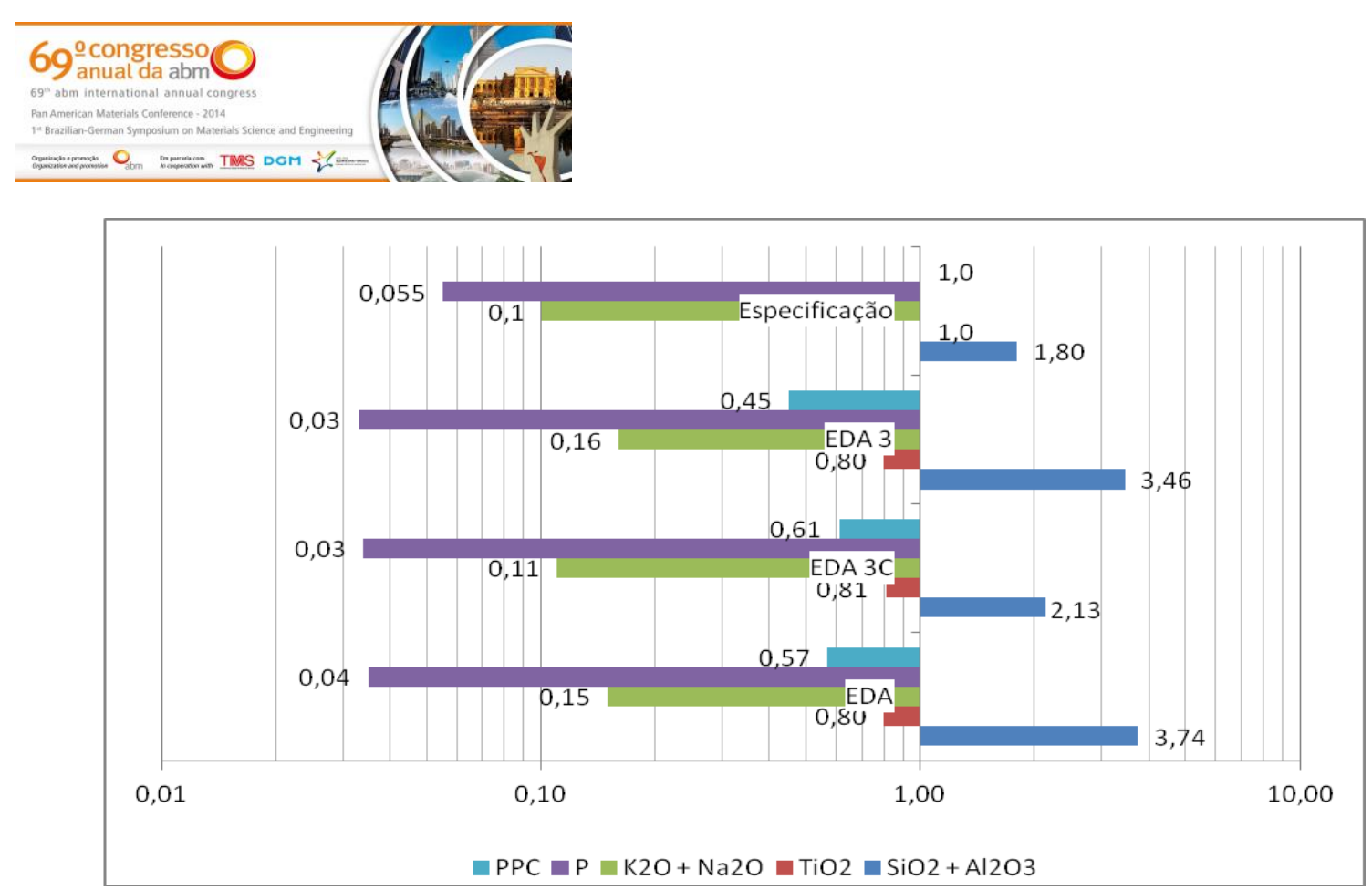

Figura 6. Limites de especificação para o concentrado final e os resultados dos testes de flotação para os contaminantes

\section{CONCLUSÃO}

- O Flotigam EDA 3 obteve o melhor resultado em recuperação metalúrgica de ferro $(93,33 \%)$.

- Comparando-se os três reagentes testados em bancada para a flotação catiônica reversa do minério de ferro em estudo, o Flotigam EDA $3 \mathrm{C}$ foi o reagente que forneceu um concentrado com maior teor de ferro $(67,40 \%)$ e menor teor de sílica $(1,76 \%)$ comparado com o Flotigam EDA e Flotigam EDA3.

- O presente estudo não teve como finalidade comparar o custo dos reagentes utilizados e como o Flotigam EDA 3C obteve os melhores teores de $\mathrm{Fe}$ e $\mathrm{SiO}_{2}$ no concentrado e rejeito, com recuperação metalúrgica acima do almejado (90\%), é portanto o coletor mais adequado para o circuito de beneficiamento proposto.

- Somente o teor de $\mathrm{SiO}_{2}+\mathrm{Al}_{2} \mathrm{O}_{3}$ ficou fora do especificado, que era de 1,8\%, para as três aminas testadas. A amina que mais se aproximou da especificação foi a Flotigam EDA 3C (2,13\%).

\section{Agradecimentos}

Os autores agradecem à Fundação Gorceix e a UFOP/Escola de Minas.

\section{REFERÊNCIAS}

1 Baltar CAM. Flotação no Tratamento de Minérios. Editora Universitária, 238 p., 2010.

2 Wills BA. Mineral Processing Technology: An Introduction to the Practical Aspects of Ore Treatment and Mineral Recovery. Oxford: Butterworth-Heinemann, p.267 - 352, 2007.

3 Papini RM. Efeito do tipo de amina na flotação reversa de um minério itabirítico. 1995. 189p. Dissertação de mestrado. Escola de Engenharia. Universidade Federal de Minas Gerais, UFMG, 1995.

4 Cassola MSE, Bartalini NM. Comportamento de coletores para o tratamento dos minérios de ferro através da flotação reversa. Revista Tecnologia em Metalurgia, Materiais e Mineração. 2010;6(4):215-219.

\footnotetext{
* Contribuição técnica ao 69ำ Congresso Anual da ABM - Internacional e ao 14ํㅡㄹ ENEMET - Encontro Nacional de Estudantes de Engenharia Metalúrgica, de Materiais e de Minas, 21 a 25 de julho de 2014, São Paulo, SP, Brasil.
} 